\title{
Multicultural Team Conflict Management in the Workplace
}

\author{
Chaya R \\ Department of Commerce, Karnataka State Open University, Mysuru, India \\ chayajkmanjunath@gmail.com
}

\begin{abstract}
In the workplace, diversity management is a process of creating a working environment that is both diverse and inclusive. It values what every employee brings to the table as unique so that an organization can grow and succeed accordingly. The overarching theory is that when employees come together from different backgrounds, creative problem - solving processes grow in turn. This is thanks in part to an increased amount of varying perspectives. Diversity is an essential consideration today. Diversity of the workplace means differences and similarities between people working in an organization. This diversity can be in terms of age, ethnicity, types of cognition, employment, appearance, education, ethnic groups, family background, social status, community, and more. Therefore, people who work in an organization with different demographic backgrounds make a diverse workforce. Diversity and inclusion are the mission, policies, and procedures of an organization to facilitate a diverse workforce and leverage the benefits of diversity to achieve a competitive business advantage; hence, the present study has taken.
\end{abstract}

Keywords: Diversity Management Workforce diversity and Inclusion, Sustainability measures to manage diversity, and diverse working environment.

\section{Introduction}

The notion of diversity and inclusion of the workforce gained tremendous popularity with globalization and the need for companies to expand their business internationally to reach consumers worldwide. A diverse workforce is reflecting a changing world and market place. A diverse work environment is the utmost priority. Diversity management matters a great deal in modern workplaces. That's because equality and diversity in the workplace can lead to better functioning teams, happier employees, and, on top of that, more revenue. Even though it sounds like an HR manager's dream, diversity management can turn it all into a reality. Diversity is integral to the success of any organization. It is updating your current program. The Inclusive processes, while important, only surface of what effective diversity management can look like in your workplace. The companies with strong diversity are much more likely to stand out competitively, and market shares are likely to shift towards more diverse organizations over time. Many research output has shown that workplace diversity has the ability to engender feelings of belonging in a staff complement and also leads towards more innovation, making better decision about productivity enhancement.

\subsection{Managing Diversity in the Workplace}

Managing diversity in the workplace is an effort that makes all employees feel included and part of a common effort. Evidently, this will lead to happier, satisfied, and ultimately more loyal employees, increasing the overall expertise of the workforce and reducing the costs involved in hiring and training new employees. However, the benefits of diversity go beyond individual job satisfaction and success. Companies that value diversity in the workplace are overall much more likely to yield successful results for their business itself. A recent McKinsey study presented the following findings:
- Companies in the top quartile for racial and ethnic diversity are $35 \%$ more likely to have financial returns above industry medians, and companies in the top quartile for gender diversity are $15 \%$ more likely to see the same results.

- Companies in the bottom quartile for gender and for ethnicity and race diversity are statistically less likely to achieve above - average financial returns.

- In the United States, there is a clear linear relationship between racial and ethnic diversity and better financial performance. For every $10 \%$ increase in racial and ethnic diversity on the senior - executive team, earnings before interest and taxes rise $0.8 \%$.

While correlation does not always equal causation (meaning greater gender and ethnic diversity in corporate leadership does not automatically translate into more profit), the statistics do point to the fact that when companies commit themselves to diverse leadership, their chances of success increase. The importance of diversity in the workplace is expressed not just in the understanding that working together promotes cohesion, collaboration, and happiness for employees, but that people with different backgrounds working together is essential in building a successful business.

1.2 The Best Practices for Managing Diversity in the Workplace are:

Successful management of diversity in the workplace cannot, and should not be limited to following a strict set of rules and expecting employees to follow them. Instead, aim to present the acceptance of diversity in the workplace as a choice, one that can benefit every individual in the workplace and ultimately yield positive and sustainable results. Some best practices for managing diversity in the workplace are, but are not limited to: 


\section{1) Create Common Goals}

The creation of common goals leads to the forming of common bonds. When people are united over the shared objective, they need to move forward together and work collaboratively, otherwise they will never reach their goal. This stresses the importance of teamwork and collaboration and helps employees to recognize the value of the individual contributions that are offered by their peers.

\section{2) Confront Unconscious Bias}

Unconscious biases are defined as the social stereotypes that exist about certain groups of people, formed by individuals outside of their own conscious awareness. It is impossible to eliminate unconscious bias. Everyone holds unconscious beliefs about various social and identity groups, a pattern that stems from our tendency to organize social worlds by categorizing. Recognizing this instinctive human response and working to confront it when it inhibits effective collaboration and diversity acceptance, can help to discourage this "other - ness" response in the workplace.

\section{3) Focus on Inclusion}

This goes further than being inclusive and considering workplace diversity in hiring processes. Inclusion in the workplace aims to actively seek out, embrace, and encourage different ways of approaching and solving problems. It involves the acknowledgment and thorough consideration of all viewpoints in an issue, respecting each voice and perspective equally.

\section{4) Move Away from Prohibitive Language}

Leaning into the idea of a diverse workplace, instead of thrusting rigid demands onto employees, is a much more effective way to encourage employees to accept each other. People don't always respond positively to rigid controls, especially when their understanding of how their personal beliefs impact their work life, so don't employ the same prohibitive and directional language in your diversity training as you would in regular employee training.

\section{5) Look Beyond Compliance}

The first step in building a truly inclusive organization is recognizing that diversity in the workplace is about more than complying with affirmative action initiatives and filling quotas. Rather, constructing a diverse workplace is instead about building a workforce that matches the diversity of your customer base, using differences to drive your business towards success. When you bring people together of varying backgrounds, belief systems, and cultures, you bring with them a range of work styles, thought processes, and valuable perspectives. Don't view managing diversity in the workplace as a required component of the modern business world, but rather as an essential tool in sparking employee creativity, improving company efficiency, and getting closer to your customers and clients.

\subsection{Effectively Managing Diversity in the Workplace is a Competitive Advantage in the Modern Business Market}

Organizations have long realized that diversity translates to good business. Embracing a multitude of viewpoints and cultures and valuing the wide array and style of input and efforts that results from a diverse workforce, ultimately drives innovation, improves decision - making, increases employee productivity and retention, and leads to better served customers. The goal of diversity in the workplace should be a central pillar in any organization's path towards success.

\subsection{Diversity Management in the Workplace Evolved}

Originally, diversity management was primarily about avoiding discrimination in recruitment and promoting tolerance within the company. But, over time and with multiple factors, things have evolved to where companies recognize the importance of diversity in the workplace as a key competitive advantage.

In order to show an in - depth understanding of a range of customers, a hiring policy geared toward diversity and inclusion pays dividends. That's why companies such as Airbus, Porsche, Zeiss, and Volkswagen have long since put their faith in workplace diversity. In its Wolfsburg location alone, Volkswagen employs people from over 100 countries.

\subsection{Importance and Managing Diversity in the Workplace}

A diverse workplace can help organizations in a variety of ways. Mainly, it can serve as a reflection of a diversifying world - thanks to demographic changes, globalization, and digitization, workplace diversity can help teams become better attuned to the many needs of their customers.

As a rule, diversity management is integrated into a company's HR or People function. However, some global corporations have whole teams or departments dedicated to it. These teams or employees typically help with some of the core tasks related to diversity management in the workplace, including:

- Developing inclusive hiring plans and processes

- Overall working policies that expand beyond simply hiring

- Providing diversity training and learning opportunities for all employees

- Playing the role of facilitator when it comes to communications

- Encouraging interactions that help promote workplace diversity

Given the range of tasks, it's understandable why diversity management often requires a team approach. For such a company - wide initiative, it's crucial that diversity management is done right on every level of the business.

\subsection{Diversity Management Helps Companies and HR Leaders}

Here are some of the key benefits when it comes to workplace diversity benefiting companies:

- Promoting an understanding of target groups from other cultures.

- Ensuring improvements in customer service.

- Driving innovative thinking in the company. 
- Boosting research and development.

- Optimizing decision - making processes thanks to different perspectives.

- Establishing new business relationships and partnerships.

- Opening up new markets.

- But, diversity management and managing diversity, more broadly, does not only have a positive effect on the economic potential of a company. Businesses also benefit from genuine diversity in terms of their employees.

\subsection{Diversity Management to Benefit HR Leaders}

HR departments also benefit from diversity in the workplace. When done right, it can lead to:

- Greater employee satisfaction, because the team feels understood and valued.

- An interesting and inspiring working environment for employees.

- A positive company image that attracts top talent and high potential associates.

- The enrichment of corporate culture.

- Stronger employee loyalty to the company.

- So, how can you take the importance of diversity management and make it real? Here's how diversity management is implemented in a way to drive business...

\section{Conclusion}

Purpose Diversity management plays a significant role in the organization's outcomes. Diversity management refers to organizational actions that aim to promote greater inclusion of employees from different backgrounds into an organization's structure through specific policies and programs. Organizations are adopting diversity management strategies as a response to the growing diversity of the workforce around the world. Improving diversity in the workplace is not merely an ethical issue but also improve the productivity and business performance.

After considering all the materials related to the topic it becomes a compulsion for the researchers to suggest, the ways to handle the shortcomings found during the survey. It is really a big matter of concern for all HR professionals as one side we say that we should include new trends in HR policies and on the other hand, the latest trend like workforce diversity is treated as a problem. However, this problem can be solved by adopting various policies like:

- Glass Ceilings

- Technology can Enhance Diversity

- By keeping the channels of communication open among the employees and employers

- Focus on inclusion and belonging by encouraging employee participation

- For improving productivity, quality has to be maintained and not thrown out.

- Reward the desired behaviour

- Commit to developing high - potential diverse candidates.

\section{References}

[1] Arpita Saha, (2007) "Nurturing Cultural Diversities A Leadership Challenge" HRM Review.

[2] Asmita Jha, (2009) "Need for Cross - Cultural Management" HRM Review ICFAI University Press.

[3] Ashok Chanda, (Dec 2006) "Driving Diversity Management in India: HR's Alienation" HRD News Letter Issue 9.

[4] Deshpande, A. (2014). A comparative study of workforce diversity in the service and manufacturing sectors in India. IMPACT: International Journal of Research in Business Management, 2 (3), 1 - 8.

[5] Dixit, P., \& Bajpai, B. L. (2015). Managing workforce diversity in a competitive environment. International Journal of Business and Management Invention (IJBMI), 4 (1), 1 - 11.

[6] Emiko Magoshi a, Eunmi Chang, "Diversity management and the effects on employees' organizational commitment: Evidence from Japan and Korea" (2008).

[7] Gupta, R. (2011). Workforce Diversity and Organizational performance. International Journal of Business and Management Invention, 2 (6), 36 - 41.

[8] Itam, U., \&Bagali, M. M. (2019). Diversity and Inclusion Management: A Focus on Employee Engagement. In Gender and Diversity: Concepts, Methodologies, Tools, and Applications (pp.1771 1788). IGI Global.

[9] Niyaz (2014). HRM and Diversity Management: A Case Study on Managing Diversity in Multinational Company Special Reference Infosys Limited, Global Research Analysis, 3 (4), 128 - 133.

[10] Saumya Goyal, (Aug 2009) "Diversity at Workplace" HRM Review SharbariSaha, Dewpha Mukherjee

[11] Singh, S., Ganguli, S., \& David, R. (2017). Women Workforce Attrition Dynamics in Indian IT/ITES Sector. Qualitative Report, 22 (5), 1211 - 1226.

[12] Solanki, R. B., \& Saxena, A. (2016). Workforce diversity and its impact on productivity. Prestige International Journal of Management and Research, 10 (1), $33-48$.

[13] Patra, (2008) "Cross - cultural Issues Intricacies and Ignarance" HRM Review ICFAI University Press

[14] Roberge, M. É., \& Van Dick, R. (2010). Recognizing the benefits of diversity: When and how does diversity increase group performance?. Human Resource management Review, 20 (4), 295 - 308.

[15] Taylor H. Cox, (Aug1991) "Managing cultural diversity: implications for organizational competitiveness" The Academy of Management Executive Vol.5 No.3 pp.45 - 56. 